\title{
DESIGN OF GEODETIC NETWORKS BASED ON OUTLIER IDENTIFICATION CRITERIA: AN EXAMPLE APPLIED TO THE LEVELING NETWORK
}

\section{Planejamento de redes geodésicas baseado no critério de identificação de outlier: um exemplo aplicado à rede de nivelamento}

Vinicius Francisco Rofatto ${ }^{1,2}$ - ORCID: http://orcid.org/0000-0003-1453-7530

Marcelo Tomio Matsuoka1,2 - ORCID: http://orcid.org/0000-0002-2630-522X

Ivandro Klein ${ }^{3,4}$ - ORCID: http://orcid.org/0000-0003-4296-592X

${ }^{1}$ Universidade Federal de Uberlândia, Instituto de Geografia, Curso de Engenharia de Agrimensura e Cartográfica, Monte Carmelo - MG, Brasil.

${ }^{2}$ Universidade Federal do Rio Grande do Sul, Programa de Pós-Graduação em Sensoriamento Remoto, Porto Alegre - RS, Brasil.

E-mail:vfrofatto@gmail.com; tomiomatsuoka@gmail.com

${ }^{3}$ Instituto Federal de Santa Catarina, Curso de Agrimensura, Florianópolis - SC, Brasil.

${ }^{4}$ Universidade Federal do Paraná, Programa de Pós-Graduação em Ciências Geodésicas, Curitiba- PR, Brasil.

E-mail: ivandroklein@gmail.com

Received in May 24 $4^{\text {th }}, 2017$

Accepted in February 26 $6^{\text {th }}, 2018$

\section{Abstract:}

We present a numerical simulation method for designing geodetic networks. The quality criterion considered is based on the power of the test of data snooping testing procedure. This criterion expresses the probability of the data snooping to identify correctly an outlier. In general, the power of the test is defined theoretically. However, with the advent of the fast computers and large data storage systems, it can be estimated using numerical simulation. Here, the number of experiments in which the data snooping procedure identifies the outlier correctly is counted using Monte Carlos simulations. If the network configuration does not meet the reliability criterion at some part, then it can be improved by adding required observation to the surveying plan. The method does not use real observations. Thus, it depends on the geometrical configuration of the network; the uncertainty of the observations; and the size of outlier. The proposed method is demonstrated by practical application of one simulated leveling network. Results showed the needs of five additional observations between adjacent stations. The addition of these new observations improved the internal reliability of approximately $18 \%$. Therefore, the final designed network must be able to identify and resist against the undetectable outliers - according to the probability levels.

Keywords: Reliability, Outlier, Numerical Simulation, Monte Carlo, Design of geodetic networks.

How to cite this article: Rofatto, V.F., et al. Design of geodetic networks based on outlier identification criteria: an example applied to the leveling network. Bulletin of Geodetic Sciences, Vol. 24, issue 2, 152-170, Apr-Jun, 2018. 


\section{Resumo:}

Nós apresentamos um método de simulação numérica para planejamento de redes geodésicas. O critério de qualidade considerado é baseado no poder do teste do procedimento estatístico data snooping. Esse critério expressa a probabilidade do procedimento data snooping de identificar corretamente um outlier. Em geral, o valor do poder do teste é sempre desconhecido na prática (definido na teoria). Porém, com o advento de computadores mais rápidos e sistemas de armazenamento de dados de maior capacidade, o poder do teste pode ser estimado por meio de simulações numéricas. O número de experimentos que o procedimento data snooping identifica corretamente um outlier é quantificado por meio do método Monte Carlo de simulação. Se a configuração inicial da rede não atender o critério de confiabilidade, então uma nova observação é adicionada no projeto da rede. O método não faz uso de observações reais coletadas em campo, dependendo apenas da configuração geométrica da rede, das incertezas das observações e da magnitude dos outliers. A eficiência do método é verificada por meio de um exemplo numérico de uma rede de nivelamento geométrico simulada. Os resultados mostraram a necessidade de cinco observações adicionais entre os pontos adjacentes. A adição destas novas observações melhorou a confiabilidade interna da rede de aproximadamente $18 \%$. Portanto, a rede é projetada de modo que seja capaz de identificar outliers e ainda resistir a outilers não identificados nas observações - de acordo com os níveis de probabilidade.

Palavras-chave: Confiabilidade, Outlier, Simulação Numérica, Monte Carlo, Redes Geodésicas.

\section{Introduction}

Geodetic networks are essential for the most geodetic engineering projects, such as monitoring the position and deformation of man-made structures (bridges, dams, power plants, tunnels, ports, etc.), to monitor the crustal deformation of the Earth, to implement an urban and rural cadastre, to establish and maintain a geospatial reference frame. Before the installation of geodetic marks and gathering of survey data, geodetic networks should be designed according to the pre-established quality criteria, such as precision, reliability and costs. The precision is related to the covariance matrix of estimated parameters (i.e. point's coordinates or displacement of points). The ability of the measurements scheme to identify outliers in the observations as well as their effects on estimated parameters are associated with the measures of reliability. Finally, the cost is related to the effort required to implement the design and related expenses (i.e. it expressed in terms of the observation schedule). Therefore, the design problem can be formulated as: "finding the optimum solution that increases the precision and reliability of the network and, at the same time, it has the lowest possible cost". In other words, a network should be designed in such a way that:

$$
\boldsymbol{\Phi}_{p}+\boldsymbol{\Phi}_{\mathrm{r}}+\boldsymbol{\Phi}_{\mathrm{c}}^{-1} \rightarrow \max
$$

$\boldsymbol{\Phi}_{\boldsymbol{p}}, \boldsymbol{\Phi}_{\boldsymbol{r}}$ and $\boldsymbol{\Phi}_{\boldsymbol{c}}$ are weight coefficients for precision, reliability and cost, respectively. Additional criteria such as sensitivity to detect displacements or deformation parameters of certain magnitude can also be considered (see e.g. Vaníček et al., 1990; Kuang, 1991; Even-Tzur, 2002; Erdogan and Hekimoglu, 2014). The design problem have been widely developed and investigated since the pioneering work of Helmert (1868). Thenceforth, a series of papers have 
been published on the development of the new algorithms by simulated examples and real applications (see e.g. Baarda, 1973; Grafarend, 1974; Baarda, 1977; Koch, 1982; Knight et al., 2010; Hekimoglu et al., 2011; Hekimoglu and Erdogan, 2012; Klein et al., 2012; Klein, 2014). Although the design of geodetic networks is a widely investigated topic, there are open issues requiring further research.

The design problem can be solved by the following methods:

- Trial-and-error (e.g. Pelzer, 1980; Grafarend and Sanso, 1985);

- Analytical (e.g. Schaffrin, 1981; Grafarend and Sanso, 1985; Cross, 1985; Schaffrin, 1985; Xu, 1989; Kuang, 1991, 1996; Blewitt, 2000; Amiri-Simkooei, 2004; Eshagh, 2005; Bagherbandi et al. 2009; Dalmolin and Oliveira, 2013; Mehrabi and Voosoghi, 2014; Eshagh and AlizadehKhameneh, 2015); and

- Intelligent or meta-heuristic (e.g.Simulated Annealing by Johnson and Wyatt 1994; Baselga, 2011; Genetic Algorithm by Sahabi et al. 2008; Dwivedi and Dikshit 2013; Graph Theory by Kortesis and Dermanis,1987; Artificial Neural Networks by Jwo and Chen, 2006; and particle swarm optimization algorithm by Yetkin et al. 2011).

However, most of these studies are based on theoretical criteria, such as criteria matrices (Baarda, 1973), error ellipses or ellipsoids (Vaníček and Krakiwsky, 1986) and redundancy numbers (Amiri-Simkooei, 2001a, 2001b). Unlike these, in this paper, we purpose an alternative method based on Monte Carlo simulation technique (MCS) to design a geodetic network in the sense of high reliability.In the context of reliability, we highlight that the vast majority of the methods consider the redundancy numbers of the observations as reliability criterion (e.g.: Baarda, 1968; Amiri-Simkooei et al. 2012; Yetkin, 2013). Here, on the other hand, the reliability criterion is based on the power of the test of iterative data snooping testing procedure.

We also highlight that the proposed method discards the use of the observation vector of GaussMarkov model. In fact, the only needs are the geometrical network configuration (given by Jacobian matrix); the uncertainty of the observations (given by nominal standard deviation of the equipment); and the magnitude intervals of the outliers. The random errors are generated artificially from the normal statistical distribution, while the magnitude of outliers is selected using standard uniform distribution.

The paper is organized as follows:

- Section 2: contains the preliminary concepts.

- Section 3: contains the background regarding the theory within our scope.

- Section 4: the method proposed here for designing geodetic networks is presented.

- Section 5: a numerical example of the proposed method is given for a leveling network.

- Section 6: summarizes the conclusions and gives recommendations for future studies 


\section{Preliminary Concepts}

Here, the term outlier is defined according to Lehmann (2013): "an outlier is an observation that is so probably caused by a gross error that it is better not used or not used it is". One of the wellknown methods for outlier identification in geodetic data analysis is Baarda's testing procedure. This method was proposed by Baarda (1968) and consists of three steps (see e.g. Teunissen 2006): detection (also known as overall model test), identification (also known as data snooping) and adaption (a corrective action, such as elimination of identified observation as an outlier).

At each iteration, only a single observation can be identified in the data snooping procedure. Once an identified observation is excluded, the least squares estimation (LSE) adjustment is restarted without the rejected observation and again the identification step (data snooping) is applied. Of course, if redundancy permits, this procedure is repeated until none identification. This procedure is called "iterative data snooping" (e.g. Teunissen, 2006). In this paper we are exclusively concerned with iterative data snooping procedure (DS).

Since DS is based on a statistical hypothesis testing with an alternative hypothesis for each observation, it may lead to a false decision as follows:

- Type I error or false alert (probability level $\alpha$ ) - Probability of identifying an outlier when there is none;

- Type II error or missed detection (probability level $\beta$ ) - Probability of non-identifying an outlier when there is at least one; and

- Type III error or wrong exclusion (probability level k) - Probability of misidentification a nonoutlying observation as an outlier, instead of the outlying one. This type of error decision was introduced by Hawkins (1980) and Förstner (1983).

The rate of type I decision error in a binary hypothesis test (i.e., with a single alternative hypothesis) can be selected by the user. The rate of type II decision error cannot. Lehmann and Voß-Böhme (2017) also point out that a test statistic with a low rate of type II is said to be powerful in the binary hypothesis case, when only a single alternative hypothesis is considered. However, in case of multiple alternative hypotheses (i.e., DS case), without considering the Type III error, there is a high risk of over-estimating the successful identification probability (see e.g. Yang et al. 2013). On the other hand, the confidence level is the probability that a non-outlying observation is correctly ignored; the power of the test is the probability that an outlier is correctly identified. Therefore, the confidence level and the power of the test are the probabilities of the test result leading to correct decisions, as opposed to the occurrence of type I, II and III errors (see, for example, Förstner, 1983; Teunissen, 2006; Klein et al., 2015b). In addition to these probabilities, the DS can identify more observations than real number of outliers (Rofatto et al., 2017).

Many of the relevant probabilities in this contribution are multivariate integrals over complex regions (Teunissen, 2017). They therefore need to be computed by means of numerical simulation such as MCS. The basic idea is to approximate probability distributions by frequency distributions of computer random experiments performed using pseudo random numbers. Therefore, as pointed out Lehmann (2012), MCS methods are used whenever the functional relationships are analytically not tractable, as is the case for DS. This simulation technique based on the pioneering idea of Hekimoglu and Koch (1999) has been recently applied in geodesy. For 
example, Ryan and Lachapelle (2001) used simulations to obtain the minimal detectable bias polygon for the case of two outliers; Lehmann and Scheffler (2011) used MCS method to solve the problem how to determine the optimal levels of Type I error probabilities for global and local tests in DS; Lehmann (2012) used MCS method to improve the critical values of the test statistics; Niemeier and Tengen (2017) extended the classical concept of geodetic network adjustment by combining the uncertainty modeling and MCS.

\section{Data Snooping Procedure: a particular case of statistical testing procedures for identification of outliers based on maximum likelihood ratio}

The mathematical model generally adopted in geodetic data analysis is the linear(ised) GaussMarkov model, given by (Koch, 1999):

$$
\boldsymbol{e}=\boldsymbol{y}-\boldsymbol{A} \boldsymbol{x}
$$

where $\boldsymbol{e}$ is the $\mathrm{n} \times 1$ random error vector, $\boldsymbol{A}$ is the $\mathrm{n} \times \mathrm{u}$ design (or Jacobian) matrix, $\boldsymbol{x}$ is the $\mathrm{u} \times 1$ unknown parameters vector and $\boldsymbol{y}$ is the $\mathrm{n} \times 1$ observations vector.

The most employed solution for a redundant system of equations ( $n>u$ and full column rank) is the weighted least squares estimator (WLSE) for the vector of unknowns $(\hat{\boldsymbol{x}})$ :

$$
\hat{\boldsymbol{x}}=\left(\boldsymbol{A}^{T} \boldsymbol{W} \boldsymbol{A}\right)^{-1}\left(A^{T} \boldsymbol{W} \boldsymbol{y}\right)
$$

in which $\boldsymbol{W}$ is the $\mathrm{n} \times \mathrm{n}$ weight matrix of the observations, taken as $\boldsymbol{W}=\boldsymbol{\sigma}_{\mathbf{0}} \mathbf{2} \boldsymbol{\Sigma} \boldsymbol{y}$, where $\boldsymbol{\sigma}_{\mathbf{0}}{ }^{2}$ is the variance factor and $\boldsymbol{\Sigma} \boldsymbol{y}$ is the covariance matrix of the observations; if $\boldsymbol{\Sigma} \boldsymbol{y}$ is diagonal, one speaks of weighted LSE (WLSE); if it is full, generalized LSE (GLSE). Teunissen (2003) demonstrates the geometric interpretation of the LSE. More details about LSE estimation can be seen in Ghilani (2010).

If there are only random errors in the observations, the LSE is the best linear unbiased estimator (BLUE) for the unknown parameters; if the observational errors follow the multivariate normal distribution with mean $\mu=0$ and covariance matrix $\boldsymbol{\Sigma} \boldsymbol{y}$, the LSE coincides with the maximum likelihood estimator (Teunissen, 2003). However, the LSE is no longer optimal in the presence of systematic and/or outliers in the observations. In other words, despite optimal properties for LSE, they lack robustness or insensitivity to outliers in observations (Huber, 1964; Rousseeuw and Leroy, 1987; Lehmann, 2013). Therefore, statistical testing procedures for detection and identification of outliers have been developed.

Quality control to identify outliers in geodetic measurements has been widely investigated since the pioneering work of Baarda (1968). In the sense of LSE, statistical testing procedures for detection and identification of outliers are based on maximum likelihood ratio. Consider a null hypothesis $H_{0}$ for the parameters of the population probability distribution of an observation vector $y$. Consider further an alternative hypothesis $H_{A}$ for these parameters, constructed in a way that $H_{0}$ is a subset of $H_{A}$. Thus, in the general case, the maximum likelihood ratio " $\lambda(y)$ " between $H_{0}$ and $H_{A}$ is given by (Larson, 1974):

$$
\lambda(y)=\frac{\max p\left(y \mid H_{0}\right)}{\max p\left(y \mid H_{A}\right)}
$$


where max $p\left(y \mid H_{0}\right)$ is the maximum of the probability density function ( $\left.p d f\right)$ of $y$ under $H_{0}$ and $\max p\left(y \mid H_{A}\right)$ is the maximum of the pdf of $y$ under $H_{A}$. As the null hypothesis is defined so that its sample space is contained in the sample space of the alternative hypothesis, the ratio in Equation4 lies in the interval of $0 \leq \lambda(y) \leq 1$ (Teunissen, 2006).

The test criterion for the maximum likelihood ratio is given by (Larson, 1974):

$$
\text { Do not reject } \mathrm{H}_{0} \text { if } \lambda(\mathrm{y}) \geq \mathrm{c}
$$

where $\mathrm{c}>0$ is the critical value for the test according to the significance level $\alpha$ stipulated (for more details, see Larson, 1974; Teunissen, 2006).

Assuming normally distributed observation errors, a general case of hypothesis testing in linear models is formulated as Teunissen(2006):

$$
H_{\mathbf{0}}: \boldsymbol{E}\{\boldsymbol{y}\}=\boldsymbol{A} \boldsymbol{x} \quad \text { vs } \quad H_{A}: \boldsymbol{E}\{\boldsymbol{y}\}=\boldsymbol{A} \boldsymbol{x}+\boldsymbol{C}_{\boldsymbol{y}} \nabla ; \nabla \neq \mathbf{0}
$$

where $H_{0}$ is the null hypothesis (namely, absence of outliers in the observations) and $H_{A}$ is an alternative hypothesis (presence of " $q$ " outlying observations in at certain known locations). The quantity $\boldsymbol{C}_{\boldsymbol{y}}$ defines the non-random error model (in this context called outlier model) with dimension $\mathrm{n} \times q$ and $\nabla$ is the corresponding vector of $q$ outliers. The dimension of $\nabla$ should be comprised between $1 \leq q \leq n-u$. For example, if $\mathrm{n}=5$ and $q=2$, then a possible outlier model is $\boldsymbol{C}_{\boldsymbol{y} 5 \boldsymbol{x}_{2}}=\left[\begin{array}{lllll}1 & 0 & 0 & 0 & 0 \\ 0 & 0 & 1 & 0 & 0\end{array}\right]$ and $\boldsymbol{\nabla}_{\mathbf{2 x \mathbf { 1 }}}=\left[\begin{array}{c}\boldsymbol{\nabla}_{1} \\ \boldsymbol{\nabla}_{3}\end{array}\right]$. (one outlier in each observation $y_{1}$ and $y_{3}$ ). For more details about error models, see e.g. Lehmann and Lösler (2016). The performance of the statistic test $T_{q}$ for multiple outliers can be found, for example, in Klein et al. (2015a) and Klein et al. (2017).

DS procedure is a particular case of maximum likelihood ratio test when only one outlier $(q=1)$ is present in the data set at a time (see e.g. Baarda, 1968; Pope, 1976; Berber and Hekimoglu, 2003; Lehmann, 2012). Therefore, the outlier model for $q=1$ is a $n \times 1$ unit vector with 1 in its $i^{\text {th }}$ entry and zeros in the remaining (e.g. $\boldsymbol{c}_{y_{\mathbf{n} x 1}}=\left[\begin{array}{llllllll}0 & 0 & \ldots & 1_{i} & 0 & \ldots & 0 & 0\end{array}\right]^{T}$ ), and $\nabla$ is a scalar value with the outlier at $i^{\text {th }}$ observation being tested. If we consider one outlying observation in at certain known locations $(q=1)$, then the maximum likelihood ratio test for $D S\left(T_{q=1}\right)$ is given by (Teunissen, 2006):

$$
\mathrm{T}_{q=1}=\hat{\boldsymbol{e}}_{0}^{T} \sum_{y}^{-1} \boldsymbol{c}_{y}\left(\boldsymbol{c}_{y}^{T} \sum_{y}^{-1} \sum_{\hat{e}_{0}} \sum_{y}^{-1} \boldsymbol{c}_{y}\right)^{-1} \boldsymbol{c}_{y}^{T} \sum_{y}^{-1} \hat{\boldsymbol{e}}_{0}
$$

where $\hat{\boldsymbol{e}}_{\mathbf{0}}$ and $\sum_{\hat{\boldsymbol{e}}_{0}}$ is the estimated random error vector and a posteriori covariance matrix of the estimated random error computed by LSE into $\mathrm{H}_{0}$, respectively.

Under $H_{0}$, observation errors are zero-mean (multivariate) normally distributed. The null hypothesis is rejected if the following test statistic $\left(T_{q}=1\right)$ of the $i^{\text {th }}$ observation being tested exceeds a given critical value $K_{\alpha} . K_{\alpha}$ is the critical value for the test according to the significance level $\alpha$. Under the null hypothesis, the test statistic $T_{q}$ follows the central chi-squared distribution with one degree of freedom; under the alternative hypothesis, the test statistic $T_{q}$ follows the non-central chi-squared distribution with one degree of freedom and non-centrality parameter $\delta$. The non-centrality parameter $\delta$ expresses the separation between the null and alternative hypotheses, that is, (see Figure 1): 


$$
\begin{gathered}
\text { Reject } \mathrm{H}_{0} \text { if: } \mathrm{T}_{q=1}>K_{\alpha} \\
H_{0}: \mathrm{T}_{q=1} \sim \chi_{(1,0)}^{2} ; H_{A}: \mathrm{T}_{q=1} \sim \chi_{(1, \delta)}^{2}, \text { with } \delta=c_{y}^{T} \sum_{y}^{-1} \sum_{\hat{e}_{0}} \sum_{y}^{-1} c_{y} \nabla^{2}
\end{gathered}
$$

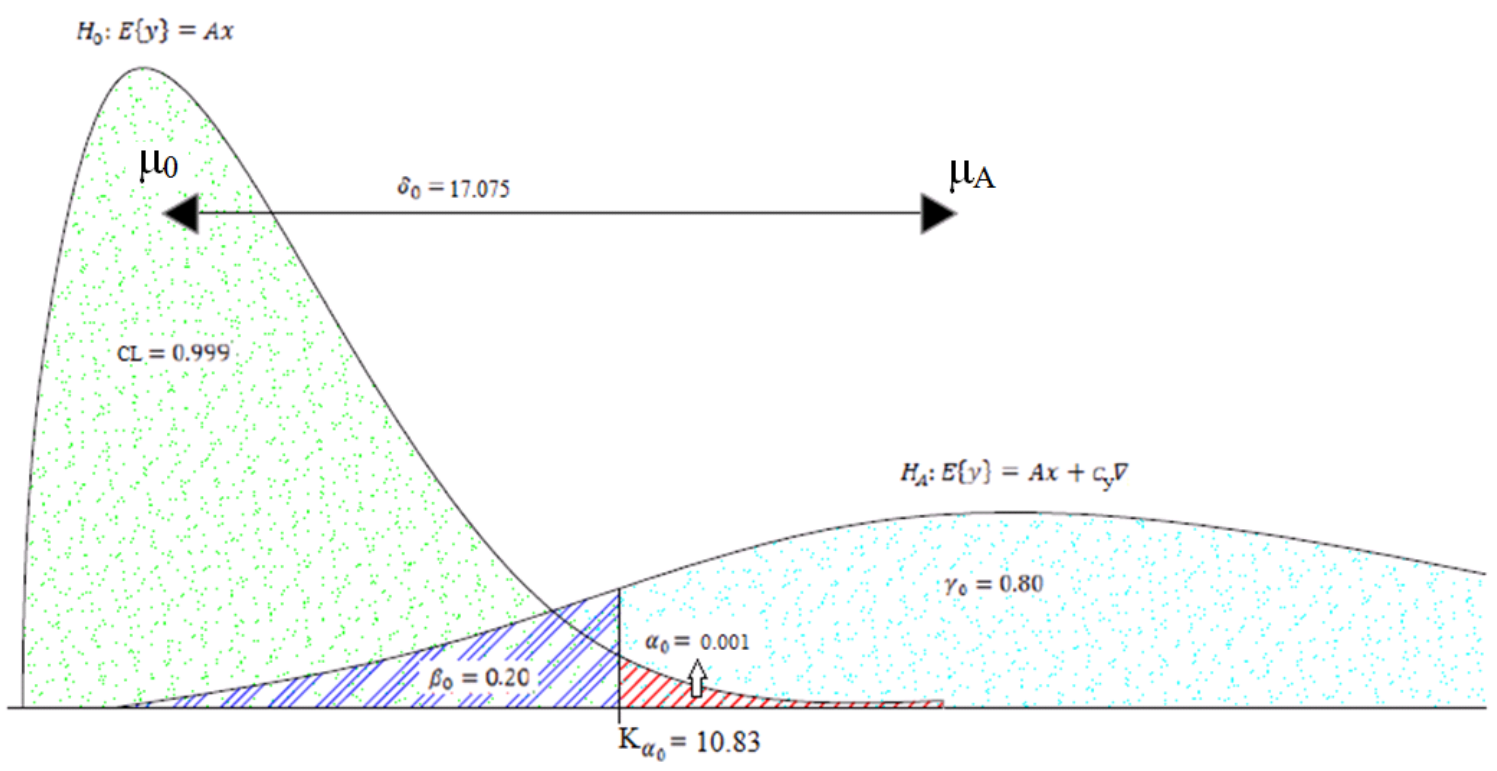

Figure 1: Probability levels related to testing hypotheses of DS.

In the Figure 1 , the $\mu_{0}$ is the expectation of the $H_{0}$ hypothesis and the $\mu_{A}$ is the expectation of the $H_{A}$ hypothesis. It should be noted that the test statistic $T_{q}$ in equation (8) is a particular case of generalized test statistic, when $q=1$. Important to mention also that the critical value follows from a chi-squared distribution with one degree freedom at a significance level of $\alpha$ in a onetailed test. Baarda (1968) and Teunissen (2006) demonstrate that if $q=1$, then the test statistics (equation 7) can also be formulated based on a standard normal distribution in a two-tailed test (so-called $w$-test). Both the chi-squared and normal distribution tests are equivalent. Usually in geodesy, the value of $\alpha$ is set between $0.1 \%$ and 1\% (Kavouras, 1982; Aydin and Demirel, 2004; Lehmann, 2013). Furthermore, DS contains multiple alternative hypotheses, as each observation is individually tested. Therefore, the only observation considered contaminated by outlier is the one whose test statistic satisfies the inequalities $T_{q=1}>K_{\alpha}$. After having identified the observation most suspected of being an outlier (at given $\alpha$ ), it is excluded usually from the model, and the WLSE and DS are applied iteratively until there are no further outliers identified in the observations (Berber and Hekimoglu, 2003).

However, three types of incorrect decisions may occur into DS and its occurrence rates are associated with probability levels: the significance level $\alpha$ is the probability of a non-outlying observation be misidentified as an outlier (type I error or false positive); $\beta$ is the probability that an outlying observation not be identified as outlier (type II error or false negative); finally, a nonoutlying observation is misidentified as an outlier, instead of the outlying one (type III error given by $\kappa)$. On other hand, the confidence level (CL) is the probability that a non-outlying observation is correctly ignored, therefore, $\mathrm{CL}=1-\alpha$; the power of the test $(\gamma)$ is the probability that an outlier is correctly identified as outlier, i.e. $\gamma=1-(\beta+\kappa)$. Therefore, the $C L$ and the $\gamma$ are the probabilities of the test result leading to correct decisions, as opposed to the occurrence of type I, II and III errors (see, for example, Förstner, 1983; Teunissen, 2006; Klein et al., 2015b). Here, 
we denoted $\alpha_{0}, \beta_{0}$ and $\kappa_{0}$ as pre-established probability levels. For example, the Figure 1 shows these relationships in the DS procedure for $C L=0.999, \gamma_{0}=0.8$, so $\alpha_{0}=0.001$ and $\beta_{0}=0.20$, leading to a pre-set non-centrality parameter $\delta_{0}=17.075$ and a pre-set critical value of $K_{\alpha}=$ 10.83. Baarda (1968) provides the monograms for those interested in obtaining $\delta_{0}$ values as a function of $\alpha_{0}$ and $\gamma_{0}$ (for a given degree of freedom). Alternatively, Aydin and Demirel (2004) presented a procedure to obtain the same through approximations of the non-central chisquared distribution. The necessity of obtaining the non-centrality parameter is widespread in Geodesy (Baarda, 1968; Kavouras, 1982; Teunissen, 2006; Knight et al., 2010).

\section{Method Proposal to Design Geodetic Networks}

The method proposed here focuses on designing of the geodetic networks in terms of high reliability. Under the present proposal, the quality criterion to be considered during the design stage is based on the number of outliers correctly identified in the DS. In other words, the key to our method is to estimate the power of the test on DS using MCS. The method does not depend on the real measurements values but only on the model design, i.e. the network geometry and covariance matrix. Therefore, the computations can be performed before the observations are carried out as follows:

1. Defining the magnitude intervals of outliers based on standard deviation of observation (e.g. $\mid 3 \sigma$ to $9 \sigma \mid$, being $\sigma$ the standard deviation of observation), the significance level $\alpha_{0}$ and the desired power of the test $\gamma_{0}$. Often, a value deviating from the sample mean by more than three times $(3 \sigma)$ the sample standard deviation $\sigma$ is assumed to be an outlier (e.g.: Hekimoglu and Koch, 2000). Here, we do not discuss how to choose the outlier magnitude, because it depends on the purpose of the geodetic project. The $\alpha_{0}$ is associated to type I error. Typically a value of the level $\alpha_{0}=0.001$ is adopted (see, e.g. Baarda, 1968). However, if this level is chosen too low then we get too large critical values and many outliers remain unidentified. If on the contrary this level is chosen too high then we get too small critical values and it is likely that good observations are eliminated. Lehmann (2012) shows how to strike a balance between these impairments of parameter estimation by using MCS methods. The $\gamma_{0}$ represents the efficiency level of the DS to identify correctly an outlying observation. The $\gamma_{0}$ is equivalent to the success rate considering the probability of type II and type III errors for all network observations (Hekimoglu and Koch, 2000; Yang et al., 2013; Klein et al., 2015b).

2. Defining a priori geodetic network configuration (preliminary design matrix) as well as the observations uncertainties (preliminary of covariance matrix of the observations, including random components and the uncertainty associated with the systematic effects). The latter follows from the instrument precision, measurement techniques and field condition (Grafarend and Sanso, 1985). It is important to mention that the design matrix defined initially must have a minimum configuration to avoid rank deficiency as well as being able to detect at least one outlier as mentioned by Xu (2005) that 'in order to identify outliers, one also has to further assume that for each model parameter, there must, at least, exist two good data that contain the information on such a parameter'. For example, consider the one unknown height into a leveling network (one-dimensional - 1D). Two observations would lead to different solutions and allow the detection of an inconsistency between them. Three observations would lead to different solutions and the identification of one outlying observation, and so on. Thus, in a general case, the value for ' $q$ ' equal to the minimal number of redundant observations across 
each and every point, minus one, For more details on the choosing the number of outliers to be considered, see Klein et al. (2017).

3. Generating synthetically a sequence of " $m$ " random errors vector $e_{\mathrm{K}}, k=1, \ldots, \mathrm{m}$ of a desired statistical distribution. The " $m$ " is known as the number of Monte Carlo experiments. Usually, one assumes that the random errors of the good measurements are normally distributed with expectation zero. Thus, we generate the random errors using multivariate normal distribution, since the assumed stochastic model for random errors is based on pre-defined matrix covariance of the observations, i.e. $e \sim N\left(0, \sigma_{0}{ }^{2} \boldsymbol{\Sigma} \boldsymbol{y}\right)$. We apply the well-known Box-Muller method (Box and Muller, 1958) for generation of normal pseudo random numbers (Practically we use MATLAB's function munrnd here). On the other hand, an outlier $(q=1)$ is selected based on pre-established magnitude intervals of the outliers (see item 1 ) for each $m$ Monte Carlo experiments. Here, we use the standard uniform distribution to select the outlier magnitude (Practically we use MATLAB's function unifrnd here). The uniform distribution is a rectangular distribution with constant probability and implies the fact that each range of values that has the same length on the distributions support has equal probability of occurrence (see e.g. Lehmann and Scheffler, 2011). For example, for 10,000 Monte Carlo experiments, if the user choices a magnitude interval of the outliers of $\mid 3 \sigma$ to $9 \sigma \mid$, the probability of a $3 \sigma$ error occurring is virtually the same as $-3 \sigma$, and so on. Random and outliers are assumed to be independent (by definition) and both are combined to the total error as follow (see e.g. Kavouras, 1982):

$$
\varepsilon=e+c_{y} \nabla, \nabla \neq 0
$$

where $\boldsymbol{\varepsilon}$ is the $\mathrm{n} \times 1$ total error vector, $\boldsymbol{e}$ is $\mathrm{n} \times 1$ random errors and $\boldsymbol{c}_{\boldsymbol{y}}$ is outlier model for $q=1$ (see expression 6$)$, and $\nabla$ is a scalar value with the outlier at $i^{\text {th }}$ observation being tested. We assume that $\boldsymbol{e}+\boldsymbol{c}_{\boldsymbol{y}} \boldsymbol{\nabla} \geq+3 \sigma$ and $\boldsymbol{e}+\boldsymbol{c}_{\boldsymbol{y}} \boldsymbol{\nabla} \leq-3 \sigma$. Before computing statistical test $\mathrm{T}_{q}=1$ it is necessary to relate the random error vector $\boldsymbol{e}$ and total error vector $\boldsymbol{\varepsilon}$, since this statistical test depends on the estimated random error vector $\hat{\boldsymbol{e}}_{\mathbf{0}}$. In the sense of LSE, this relationship is given by (see Kavouras, 1982):

$$
\begin{array}{r}
\hat{e}_{0}=R \varepsilon, \\
R=I-A\left(A^{T} W A\right)^{-1} A^{T} W
\end{array}
$$

in which $\boldsymbol{R}$ is the $\mathrm{n} \times \mathrm{n}$ redundancy matrix and $\boldsymbol{I}$ is the $\mathrm{n} \times \mathrm{n}$ identity matrix.

In the equation 11 the reader should be note that the multiplication of the redundancy matrix $\boldsymbol{R}$ and the total error $\boldsymbol{\varepsilon}$ provides the estimated random error vector $\hat{\boldsymbol{e}}_{\mathbf{0}}$. Now, the $\hat{\boldsymbol{e}}_{\mathbf{0}}$ is not only composed by random errors, but also it has one of its elements contaminated by an outlier. Now it becomes possible to compute the test statistic $T_{q}=1$ considering the relation given by equation10.

4. Quantifying the success rate (fraction of outliers correctly identified, i.e. the power of the test computed by MCS, see e.g. Hekimoglu and Koch, 1999; 2000) and the misidentification rates for one outlier after having ran $m$ Monte Carlo experiments for each observation. The misidentifications are divided in two types of classes are counted in the simulations: number of experiments where the procedure yielded none observation identification (type II error - $\beta$ ); number of experiments in which the procedure identified a single observation but wrong localization (type III error, denoted here as $\kappa$ ). 
5. Checking if the lowest power of the test based on MCS $\left(\gamma_{M}\right)$ is greater than or equal to the desired power of the test $\left(\gamma_{0}\right)$ for each observation. For example, in the case of $\gamma_{0}=0.80$ and one outlier, the outlier must be identified in at least $80 \%$ of cases. Otherwise, the network must be improved until the power of the test based on MCS is greater than or equal to the pre-stipulated power of test $\gamma_{0}$. Here, a new observation is added in the one which presents the lowest power of the test based on MCS. The design stage is finished when $\boldsymbol{\gamma}_{\boldsymbol{M}}$ is greater than or equal to $\gamma_{0}$. The adding of new observations in the one less resistant to outlier in the network has been used by some authors. For example, Yetkin and Beber (2012) added the GPS (Global Positioning System) baselines to meet the robustness criterion in the design of GPS networks. The proposed method is summarized as a flowchart in Figure 2.

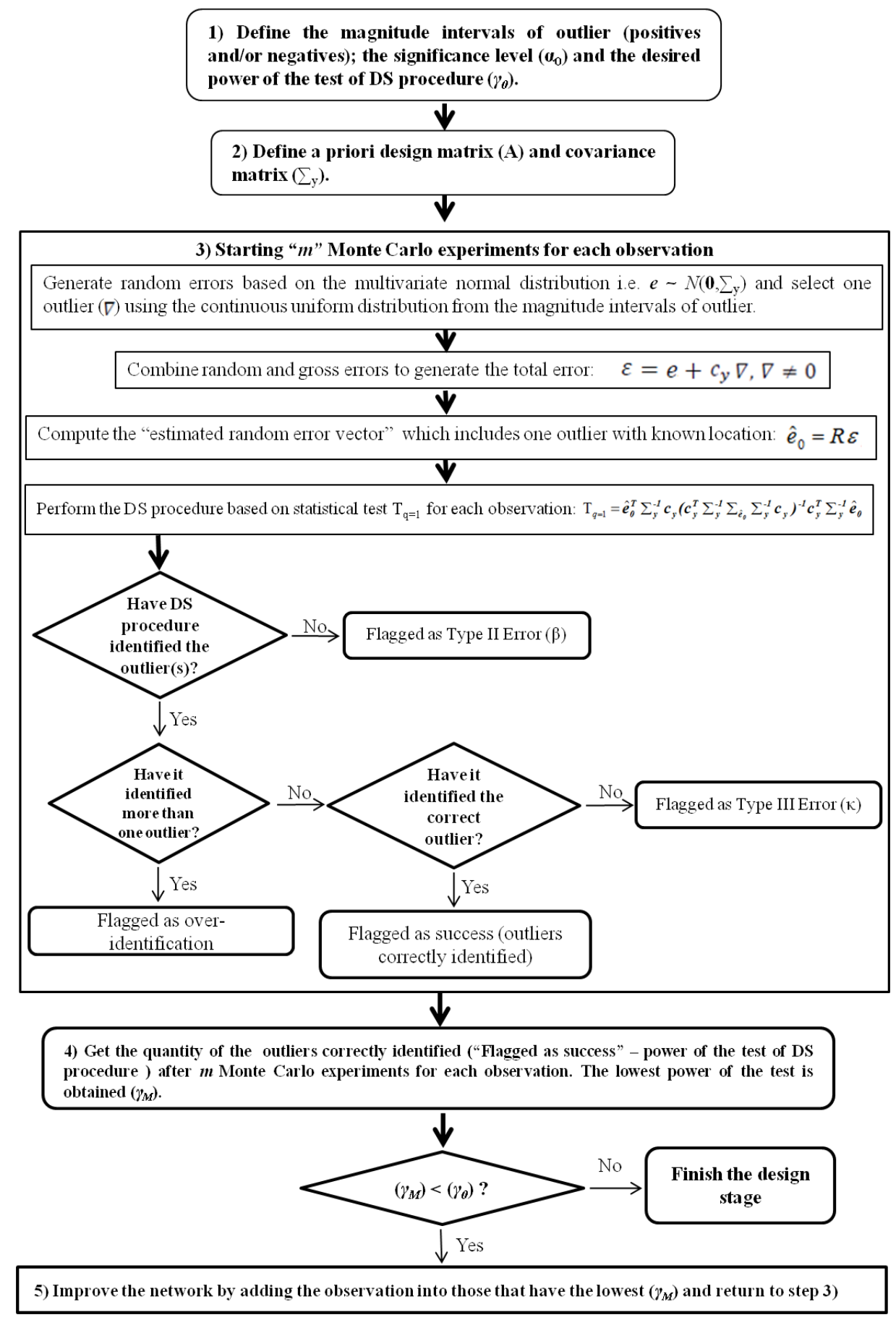

Figure 2: Flowchart of the proposed method. 


\section{Numerical Examples}

In order to demonstrate the design method in practice, in this section we apply it to a simulated closed leveling network. The goal is to illustrate the design method; further considerations about levelling networks are outside the scope of this study.

We consider a closed levelling network, with one control station (benchmark), and 4 points with unknown heights ( $A, B, C$ and $D$ ), totaling four minimally constrained points as shown in Figure 3 . The benchmark is fixed, and the distances of the adjacent and non-adjacent stations are approximately $240 \mathrm{~m}$ and $400 \mathrm{~m}$, respectively. The equipment used is a spirit level with nominal standard deviation for a single staff reading of $\pm 0.02 \mathrm{~mm} / \mathrm{m}$. Lines of sight distances are kept at $40 \mathrm{~m}$. Thus, each total height difference $\boldsymbol{\Delta} \boldsymbol{h}_{\boldsymbol{i}}$ between adjacent or non-adjacent stations is made of, respectively, three or five partial height differences $(p)$. Each partial height difference, in turn, involves one instrument setup and two sightings: forward and back. The standard deviation for each $\boldsymbol{\Delta} \boldsymbol{h}_{\boldsymbol{i}}$ equals to $\sigma_{i}= \pm \sqrt{2} p \times 40 \times 0.02 \mathrm{~mm} / \mathrm{m}$, i.e. $\sigma_{i}= \pm \sqrt{ } 2 p \times 0.8 \mathrm{~mm}$, where $p$ is 3 or 5 . The readings are assumed uncorrelated and $\boldsymbol{\sigma}_{0}^{2}=1$.

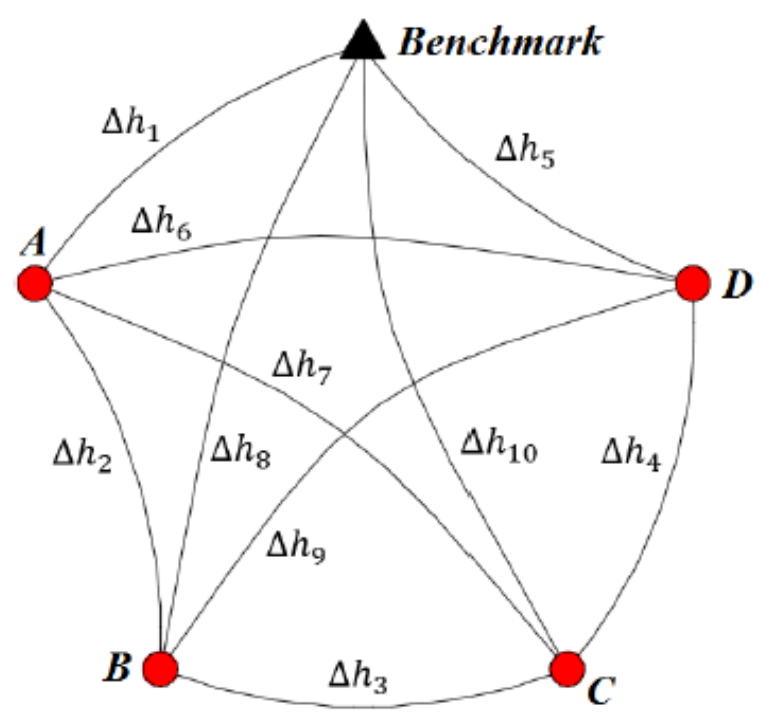

Figure 3: Simulated leveling network.

For each unknown points, there are four height difference measurements. Thus, there are $n=10$ observations, $u=4$ unknowns, and $n-u=6$ degrees of freedom in this simulation. The design matrix $(A)$ has dimension $10 \times 4$ and the covariance matrix of observations has dimension $10 \times 10$. Each station is involved in four height differences, so there are three redundant observations for the determination of each unknown.

Here, we define a threshold power of the test of DS of $\gamma_{0}=0.80$. The significance level is taken as $\alpha_{0}=0.001$ (the typically adopted value, see, e.g. Baarda, 1968), so the critical value of the $\chi^{2}$ distribution for the statistic $T_{q=1}$ is $K_{\alpha_{0}}=10.83$. Here, 15,000 Monte Carlo experiments were defined for each observation. In each experiment are performed considering positive and negative outliers between $3 \sigma$ and $9 \sigma$ magnitude intervals ( $\sigma$ being the respective standard deviation of the observation). Table 1 shows the power of the test based on MCS for each observation without considering the addition of new observations: 
Table 1: Power of the iterative DS and misidentification rates (\%) for each observation in a priori network configuration

\begin{tabular}{cc|c|c|c}
\hline Observation $\left(\Delta h_{i}\right)$ & Power of iterative DS (\%) & Type II Error & Type III Error & Over-identification \\
\hline$\Delta \boldsymbol{h}_{\mathbf{1}}$ & 66.9 & 29.9 & 2.7 & 0.5 \\
$\Delta \boldsymbol{h}_{\mathbf{2}}$ & 68.7 & 28.2 & 2.7 & 0.4 \\
$\Delta \boldsymbol{h}_{\mathbf{3}}$ & 68.4 & 28.5 & 2.7 & 0.4 \\
$\Delta \boldsymbol{h}_{\mathbf{4}}$ & 68.7 & 28.1 & 2.6 & 0.6 \\
$\Delta \boldsymbol{h}_{\mathbf{5}}$ & 72.3 & 25.3 & 1.8 & 0.6 \\
$\Delta \boldsymbol{h}_{\mathbf{6}}$ & 79.1 & 19.2 & 1.1 & 0.6 \\
$\Delta \boldsymbol{h}_{\mathbf{7}}$ & 83.5 & 15.3 & 0.5 & 0.7 \\
$\Delta \boldsymbol{h}_{\mathbf{8}}$ & 81.0 & 17.4 & 0.9 & 0.7 \\
$\Delta \boldsymbol{h}_{\mathbf{9}}$ & 83.3 & 15.5 & 0.6 & 0.6 \\
$\Delta \boldsymbol{h}_{\mathbf{1 0}}$ & 78.8 & 19.4 & 1.3 & 0.5 \\
\hline
\end{tabular}

Table 1 shows that the observation $\Delta \boldsymbol{h}_{\mathbf{1}}$ has the lowest power of the test $(66.9 \%)$ for the simulated leveling network. In other words, among the 15,000 experiments performed using MCS for this observation, 10035 outliers were correctly identified. Regarding the three classes of misidentification rates, 4485 observations were not identified (29.9\%); 405 outlying observations is misidentified (2.7\%); and there were 75 cases of over-identification (0.5\%). Figure 4 shows the power of the DS for the priori geodetic network configuration. It can be noted that the lowest power of test based on MCS $\left(\gamma_{\boldsymbol{M}}(\Delta \boldsymbol{h} \boldsymbol{l})=66.9\right)$ does not achieve the reliability criterion. Therefore, the leveling network must be improved.

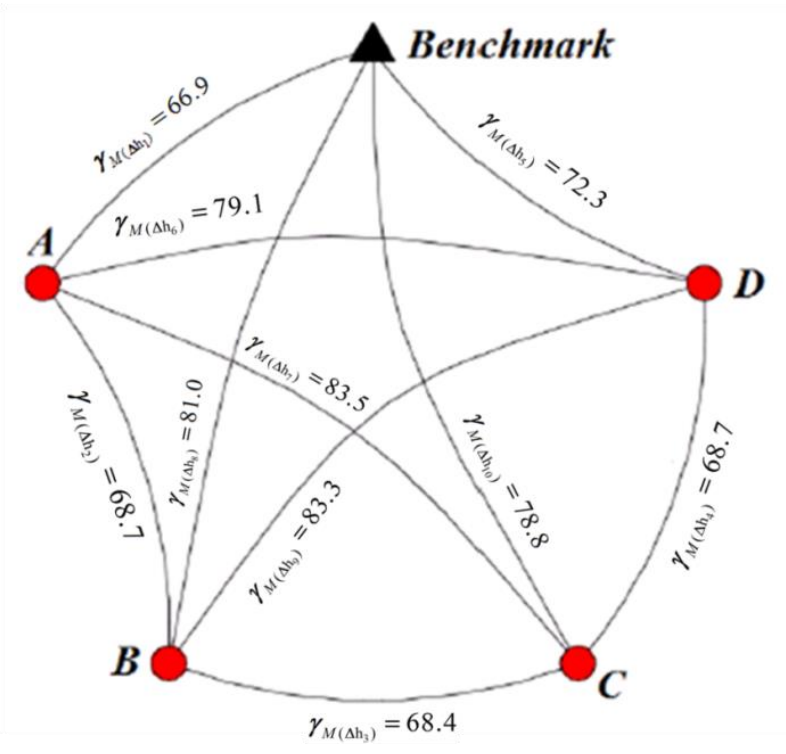

Figure 4: Power of the DS for the initial geodetic network configuration. 
According to the proposed algorithm (summarized in the Figure 2), the next task is to add a new observation among those that has the lowest power of the test. In this case, a new observation is added in the $\Delta \boldsymbol{h}_{\mathbf{1}}$, since its lowest power of the test(indicated in bold in Table 1)is less than the quality criterion (i.e. $\boldsymbol{\gamma}_{\boldsymbol{M}(\Delta \boldsymbol{h l})}=66.9 \%<\gamma_{0}=80 \%$ ). This process is repeated until the lowest power of the test is greater than or equal to reliability criterion $\left(\gamma_{M}>\gamma_{0}\right)$. Table 2 shows the power of the test based on MCS for each observation. The lowest power of the test is emboldened in the Table 2.The addition of new measurements has substantially increased the power of the DS for the simulated network. It can be noted that five new observations were added to geodetic network in order to meet the reliability criterion. These new observations are indicated in single quotation marks.

Table 2: Power of the test of the iterative DS (\%) for $\alpha_{0}=0.001$ in simulated network

\begin{tabular}{|c|c|c|c|c|c|}
\hline \multirow{2}{*}{ Observation $\left(\Delta \boldsymbol{h}_{i}\right)$} & \multicolumn{5}{|c|}{ Iteration } \\
\hline & $1^{\text {st }}$ & $2^{\text {nd }}$ & $3^{\text {rd }}$ & $4^{\text {th }}$ & $5^{\text {th }}$ \\
\hline$\Delta \boldsymbol{h}_{1}$ & 79 & 78 & 80 & 80 & 80 \\
\hline$\Delta \boldsymbol{h}_{2}$ & 72 & 73 & 80 & 80 & 80 \\
\hline$\Delta \boldsymbol{h}_{3}$ & 68 & 78 & 80 & 81 & 81 \\
\hline$\Delta \boldsymbol{h}_{4}$ & 70 & 73 & 74 & 80 & 81 \\
\hline$\Delta \boldsymbol{h}_{5}$ & 75 & 74 & 75 & 76 & 81 \\
\hline$\Delta \boldsymbol{h}_{6}$ & 81 & 80 & 82 & 83 & 84 \\
\hline$\Delta \boldsymbol{h}_{7}$ & 83 & 83 & 84 & 85 & 85 \\
\hline$\Delta h_{8}$ & 83 & 83 & 84 & 84 & 84 \\
\hline$\Delta h_{9}$ & 83 & 84 & 84 & 85 & 85 \\
\hline$\Delta \boldsymbol{h}_{10}$ & 78 & 81 & 82 & 81 & 82 \\
\hline${ }^{\prime} \Delta h_{1}{ }^{\prime}$ & 79 & 79 & 80 & 80 & 81 \\
\hline$' \Delta h 3^{\prime}$ & - & 79 & 79 & 80 & 89 \\
\hline${ }^{\prime} \Delta \boldsymbol{h}_{2}{ }^{\prime}$ & - & - & 81 & 80 & 81 \\
\hline$' \Delta \boldsymbol{h}_{4}{ }^{\prime}$ & - & - & - & 81 & 81 \\
\hline${ }^{\prime} \Delta h_{5}{ }^{\prime}$ & - & - & - & - & 81 \\
\hline
\end{tabular}

Although observations between adjacent stations (1, 2, 3, 4 and 5) are more precise, the power of the test shows that additional observations are needed to meet the quality criteria. On the other hand, the observations between the non-adjacent stations located in the center of the network are more controllable $(6,7,8,9$ and 10). In the latter case, it appears that the center of the network is the optimal location to do the observations, as can be seen in a similar way in the work of Horemuž and Jansson (2016) as well as Amiri-Simkooei, (2001b).The new observations and the power of DS associated with them are highlighted in the Figure 5. 


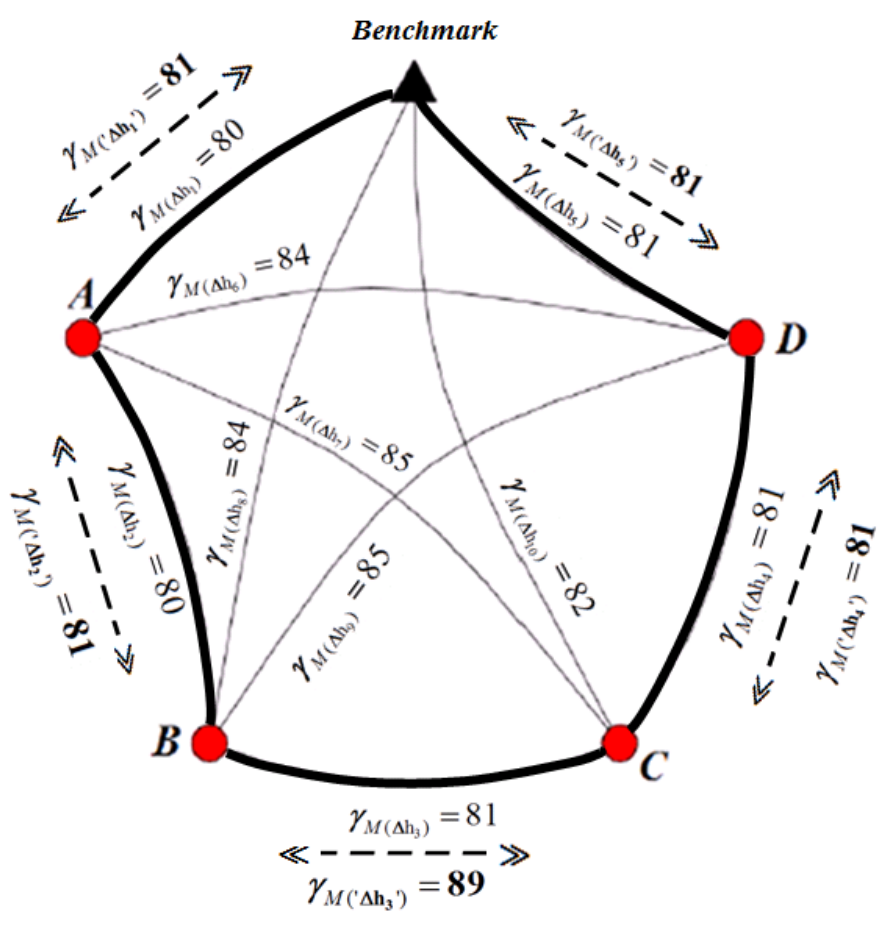

Figure 5: Final geodetic network configuration.

It is important to mention that the power of the test defined here as quality criteria was of 0.80 . The user can choose another level of this probability. However, if the user increases the level of the power of the test, in general, it also increases the cost, since more observations must be needed or other equipment of better precision must be acquired to meet the quality criteria. Furthermore, the magnitudes of the outlier and the significance level have a direct relationship. The smaller the size of the outlier to be identified, the higher the level of significance should be. However, the user must be careful not to set a significance level and a magnitude of the outlier (first step of the method) that makes the design geodetic network unfeasible from the point of view of cost. Thus, we suggest to the user to analyze the best scenario with different levels of significance (e.g. Rofatto et al., 2017). The analysis of the significance level is outside the scope of this paper and it will be addressed in a future research.

\section{CONCLUSION}

The conclusions are highlighted in the following:

- The proposed method to design a geodetic network is based on numerical simulation. The method discards the use of the observation vector of Gauss-Markov model. In fact, the only needs are the geometrical network configuration (given by Jacobian matrix); the uncertainty of the observations (given by nominal standard deviation of the equipment); and the magnitude intervals of the outliers. The proposed method seeks to maximize the internal reliability by adding new observations in the one which presents the lowest power of test based on MCS. This process is repeated until a sufficiently robust network is obtained. Therefore, it can be applied for any kind of geodetic network.

- Here, the proposed method was applied to a closed levelling network. It was defined a threshold power of the test of DS of $0.80(80 \%)$ and the significance level was taken as 0.001 
(0.1\%). 15,000 Monte Carlo experiments were defined for each observation. In each experiment are performed considering positive and negative outliers between $3 \sigma$ and $9 \sigma$ magnitude intervals. Results showed the needs of five additional observations between adjacent stations. The addition of these new observations improved the internal reliability of approximately $18 \%$, i.e. it increased the probability of the ability of the measurements scheme to identify an outlier in the set of the observations.

\section{ACKNOWLEDGEMENT}

The authors thank CNPq for financial support (proc. n. 305599/2015-1). We also appreciate the support of all members of the research group: "Quality Control in Geodesy" (http://dgp.cnpq.br/dgp/espelhogrupo/3674873915161650). Last but not least we are also thankful to the two anonymous reviewers who provided contribution to the revision of the paper.

\section{REFERENCES}

Amiri-Simkooei, A. R. 2001a. Comparison of reliability and geometrical strength criteria in geodetic networks. Journal of geodesy, 75(4), pp.227-233.

Amiri-Simkooei, A. R. 2001b. Strategy for designing geodetic network with high reliability and geometrical strength. Journal of Surveying Engineering, 127(3), pp.104-117.

Amiri-Simkooei, A. R. 2004. A new method for second order de-sign of geodetic networks: aiming at high reliability. Survey Review, 37(293), pp. 552-560.

Amiri-Simkooei, A. R.; Asgari, J.; Zangeneh-Nejad, F.; Zaminpardaz, S. 2012. Basic Concepts of Optimization and Design of Geodetic Networks. Journal of Surveying Engineering, 138(4), pp.172183.

Aydin, C.; Demirel, H. 2004. Computation of baarda's lower bound of the non-centrality parameter. Journal of Geodesy,78(4), pp. 437-411.

Baarda, W. 1968. A testing procedure for use in geodetic networks. [pdf] Delft: Publications on Geodesy, Netherlands Geodetic Commission.

Available at: <http://www.ncgeo.nl/phocadownload/09Baarda.pdf> [Accessed 1 april 2017].

Baarda, W. 1973. S-transformation and criterion matrices. Publications on Geodesy, Netherlands Geodetic Commission.

Baarda, W. 1977. Measures for the accuracy of geodetic networks. In: Symposium on optimization of design and computation of control networks, pp.419-436.

Bagherbandi, M.; Eshagh M.; Sjöberg, L. E. 2009, Multi-Objective versus Single-Objective Models in Geodetic Network Optimization. Nordic Journal of Real Estate Research, pp.7-20.

Baselga, S. 2011. Second order design of geodetic networks by the simulated annealing method. Journal of Surveying Engineering, 137(4), pp.167-173. 
Berber, M; Hekimoglu, S. 2003. What is the reliability of conventional outlier detection and robust estimation in trilateration networks? Survey Review,37(290), pp.308-318.

Blewitt, G. 2000. Geodetic network optimization for geophysical parameters. Geophysical Research Letters. 27(22), pp.3615-3618.

Box, G. E.; Muller, M. E. 1958. A note on the generation of random normal deviates. The Analls of Mathematical Statistics. 29(2), pp.610-611.

Cross, P. A. 1985. Numerical Methods in Network Design. In: Grafarend E.W., Sansò F. (eds) Optimization and Design of Geodetic Networks. Springer, Berlin, Heidelberg.

Dalmolin, Q.; Oliveira, R. 2013. Inverse eigenvalue problem applied to weigh optimisation in a geodetic network. Survey Review. 43(320), pp. 187-198.

Dwivedi, R.; Dikshit, O. 2013. A comparison of particle swarm optimization (PSO) and genetic algorithm (GA) in second order design (SOD) of GPS networks. Journal of Applied Geodesy,7(2), pp.135-146.

Erdogan, B.; Hekimoglu, S. 2014. Effect of subnetwork configuration design on deformation analysis. Survey Review. 46(335), pp.142-148.

Eshagh, M. 2005. Optimization and design of geodetic networks. Technical Report 2, Azad University, Shahr-e-Rey branch, Tehran, Iran.

Eshagh, M.; Alizadeh-Khameneh, M. 2015. Two-epoch optimal design of displacement monitoring network. Boletim de Ciências Geodésicas. 21(3), pp. 484-497.

Even-Tzur G (2002) GPS vector configuration design for monitoring deformation networks. Journal of Geodesy. 76 (8), pp 455-461.

Förstner, W. 1983. Reliability and discernability of extended gauss-markov models. In: Deut. Geodact. Komm. Seminar on Math. Models of Geodetic Photogrammetric Point Determination with Regard to Outliers and Systematic Errors, pp. 79-104.

Ghilani, C. D. 2010. Adjustment computations: spatial data analysis, 5th edn. John Wiley \& Sons, New Jersey.

Grafarend, E. W. 1974. Optimization of geodetic networks. Bollettino di geodesia e scienze affini, 33(4), pp. 351-406.

Grafarend, E. W.; Sanso, F. 1985. Optimization and design of geodetic networks. Springer Verlag, Berlin.

Hawkins, D. 1980. Identification of outliers, Chapman and Hall, London.

Hekimoglu, S.; Koch, K. R. 1999. How Can Reliability of the Robust Methods be Measured?, In Third Turkish German Joint Geodetic Days, Altan and Gründing (Eds), 1-4June, Istanbul, Turkey, pp. 179-196.

Hekimoglu, S.; Koch, K.R. 2000. "How can reliability of the test for outliers be measured?", Allg. Vermes. Nachr. 107(7), pp. 247-254.

Hekimoglu, S; Erenoglu, R. C.; Sanli, D. U.; Erdogan, B. 2011. Detecting Configuration Weaknesses in Geodetic Networks. Survey Review, 43 (323), pp.713-730.

Hekimoglu, S.; Erdogan, B. 2012. New Median Approach to Define Configuration Weakness of Deformation Networks. Journal of Surveying Engineering, 138(3), pp.101-108. 
Helmert, F.R. (1868). Studien über rationelle Vermessungen im Gebiete der höheren Geodäsie. Available at <http://digital.slub-dresden.de/id333596722> [Accessed 20 march 2017].

Horemuž, M.; Jansson, P. 2016. Optimum establishment of total station. (Technical Notes). Journal of Surveying Enginnering, 143(2) Available through: Asce Library database [Accessed 20 march 2017]

Huber, P. J. 1964. Robust estimation of a location parameter. Annals of Mathematical Statistics. 35(1), pp.73-101.

Johnson, H.; F. Wyatt. 1994. Geodetic network design for faultmechanics studies. Manuscripta Geodaetica, 19(5), pp.309-323.

Jwo, D. J.; Chen, J. J. 2006. GPS/INS Navigation Filter Designs Using Neural Network with Optimization Techniques. Advances in Natural Computation, Lecture Notes in Computer Science, Springer, Berlin, Heidelberg, 4221, pp.461-470.

Kavouras, M. 1982. On the detection of outliers and the determination of reliability in geodetic networks. PhD thesis, Fredericton: Department of Surveying Engineering, University of New Brunswick.

Klein, I.; Matsuoka, M. T.; Souza, S. F.; Collischonn, C. 2012. Design of geodetic networks reliable against multiple outliers (in Portuguese). Boletim de Ciências Geodésicas, 18(3), pp.480-507.

Klein, I. 2014. Proposal of a new method for geodetic networks design (in Portuguese). PhD thesis, Porto Alegre: Universidade Federal do Rio Grande do Sul.

Klein, I.; Matsuoka, M. T.; Guzatto, M. P.; Souza, S. F.; Veronez, M. R. 2015a. On evaluation of different methods for quality control of correlated observations. Survey Review. 47(340), pp.2835.

Klein, I.; Matsuoka, M. T.; Guzatto, M. P. 2015b. How to estimate the minimum power of the test and bound values for the confidence interval of data snooping procedure (in Portuguese). Boletim de Ciências Geodésicas. 21(1), pp.26-42.

Klein, I.; Matsuoka, M. T.; Guzatto, M. P.; Nievinski, F. G. 2017. An approach to identify multiple outliers based on sequential likelihood ratio tests. Survey Review. 49( 357), pp. 449-457.

Knight, N. L.; Wang, J.; Rizos, C. 2010. Generalised measures of reliability for multiple outliers. Journal of Geodesy. 84(10), pp 625-635.

Koch, K. R. 1982. Optimization of the configuration of geodetic networks. Deutsche Geodaetische Kommission. Munich, B, 258/III, pp.82-89.

Koch, K. R. 1999. Parameter Estimation and Hypothesis Testing in Linear Models. Berlin Heidelberg New York, Springer Verlag.

Kortesis, S.; A. Dermanis. 1987. An application of graph theory to the optimization of costs in trilateration networks. Manuscripta Geodaetica, 12, pp.296-308.

Kuang, S. 1991. Optimization and design of deformation monitoring schemes. PhD thesis, Fredericton: Department of Surveying Engineering, University of New Brunswick.

Kuang, S. 1996. Geodetic network analysis and optimal design: concepts and applications. Ann Arbor Pressinc. 
Larson, H. J. 1974. Introduction to probability theory and statistical inference. 2nd ed. New York: John Wiley \& Sons.

Lehmann, R.; Scheffler, T. 2011. Monte Carlo-based data snooping with application to a geodetic network. Journal of Applied Geodesy. 5(3-4), pp.123-134.DOI: 10.1515/JAG.2011.014

Lehmann, R. 2012. Improved critical values for extreme normalized and studentized residuals in gauss-markov models. Journal of Geodesy. 86(12), pp.1137-1146.

Lehmann, R. 2013. On the formulation of the alternative hypothesis for geodetic outlier detection. Journal of Geodesy, 87(4), pp.373-386.

Lehmann, R.; Lösler, M. 2016. Multiple Outlier Detection: Hypothesis Tests versus Model Selection by Information Criteria. Journal of Surveying Engineering, 142(4):04016017.

Lehmann, R.; Voß-Böhme, A. 2017. On the statistical power of Baarda's outlier test and some alternative. Journal of Geodetic Science. 7(1), pp. 68-78.

Mehrabi, H.; Voosoghi, B. 2014. Optimal observational planning of local GPS networks: assessing an analytical method. Journal of Geodetic Science. 4(1), pp. 87-97.

Niemeier, W.; Tengen, D. 2017. Uncertainty assessment in geodetic network adjustment by combining GUM and Monte-Carlo-simulations. Journal of Applied Geodesy. DOI: 10.1515/jag2016-0017.

Pelzer, H. 1980. Some criteria for the accuracy and the reliability of networks. Deutsche Geodatische Kommission, Wittwer-Verlag, Stuttgart, pp. 273-304

Pope, A. J. 1976. The statistics of residuals and the detection of outliers. NOAA Technical Report NOS65 NGS1, US Department of Commerce, National Geodetic Survey Rockville, Maryland.

Rofatto, V. F.; Matsuoka, M. T.; Klein, I. 2017. An Attempt to Analyse Baarda's Iterative Data Snooping Procedure based on Monte Carlo Simulation. South African Journal of Geomatics. DOI: http://dx.doi.org/10.4314/sajg.v6i1.1.

Rousseeuw, P. J.; Leroy, A. M. 1987. Robust regression and outlier detection. John Wiley \& Sons, New Jersey.

Ryan, S.; Lachapelle, G. 2001. Marine positioning multiple multipath error detection. Hydrographic Journal, pp. 3-11.

Sahabi, H.; Rajabi, M. A.; Blais, J. A. R. 2008. Optimal Configuration Design of Geodetic Networks Using Penalty Function-Based Genetic Algorithm. Geophysical Research Abstracts, EGU General Assembly 2008.

Schaffrin, B. 1981. Some proposals concerning the diagonal second order design of geodetic networks. Manuscripta Geodetica, 6, pp. 303-326.

Schaffrin, B.1985. Aspects of network design, optimization and design of geodetic networks. Springer Verlag.

Teunissen, P. J. G. 2003. Adjustment Theory: An Introduction. Delft University Press, Delft.

Teunissen, P. J. G. 2006. Testing theory: An Introduction. 2nd ed. VSSD, Delft.

Teunissen, P. J. G. 2017. Distributional theory for the DIA method. Journal of Geodesy. pp.1-22. DOI: 10.1007/s00190-017-1045-7.

Vaníček, P.; Krakiwsky, E. J. 1986. Geodesy-the concepts. 2nd ed. Elsevier, Amsterdam. 
Vaníček, P.; Krakiwsky, E. J.; Craymer, M. R.; Gao, Y.; Ong, P. S. 1990. Robustness analysis. Final contract report, Department of Surveying Engineering Technical Report No. 156, University of New Brunswick, Fredericton, New Brunswick, Canada, pp. 116.

Xu, Peiliang. 1989 Multi-Objective Optimal Second Order Design of Networks. Bulletin géodésique (Journal of Geodesy), 63 (3), pp. 297-308.

$X u, P .2005$. Sign-constrained robust least squares, subjective breakdown point and the effect of weights of observations on robustness. Journal of Geodesy, 79(1), pp.146-159.

Yang, L.; Wang, J.; Knight, N. L.; Shen, Y. 2013. Outlier separability analysis with a multiple alternative hypotheses test. Journal of Geodesy, 87(6), pp.591-604.

Yetkin, M.; Inal, C.; Yigit, CO. 2011. The optimal design of baseline configuration in GPS networks by using the particle swarm optimisation algorithm. Survey Review. 43(323), pp.700-712.

Yetkin, M.; Berber, M. 2012. GPS baseline configuration design based on robustness analysis. Journal of Geodetic Science, 2(3), pp.234-239.

Yetkin, M. 2013. Metaheuristic optimisation approach for designing reliable and robust geodetic networks. Survey Review, 45(329), pp.136-140. 